\title{
Numerical Investigation of the Effects of Baffles in a Shell and Tube Heat Exchanger
}

\author{
Mehmet Turgay PAMUK \\ Bahçeşehir University \\ Faculty of Engineering and Natural Sciences \\ Istanbul, Turkey \\ E-mail: turgaypamuk@hotmail.com
}

\begin{abstract}
This numerical study examines the effects of the baffles added to the fluid (oil) flow path to be cooled in a shell and tube heat exchanger. The heat transfer rate in the case without baffles is compared to the cases where the baffles are added in the oil flow path. The comparison shows a remarkable increase in heat transfer, but on the other hand leads to higher pumping costs due to a higher pressure loss. CFD simulation can optimize the design of shell and tube heat exchangers by changing the number, size and position of the baffles. The CFD simulation package used here is the commercial software ANSYS Fluent ${ }^{\oplus}$. The CFD model contains all details of the geometric and material properties, so that the solution reflects all physical phenomena such as rate of heat transfer, temperature, velocity and pressure distributions within the computational domain. The approach used here provides heat exchanger manufacturers with valuable design information without having to produce prototypes that are based not only on expensive, but also on time-consuming trial and error methods.
\end{abstract}

Keywords: Heat Transfer, Heat Exchangers, CFD simulation,

\section{Introduction}

A heat exchanger is a system that facilitates the transfer of thermal energy from one fluid to another. They are indispensable devices for many applications from HVAC to chemical processes, power plants to various sectors in industrial production. In the simplest heat exchangers hot and cold fluids are mixed directly, while in the more common types are those where fluids are separated by a wall. This second type can range from a simple separation between two flowing fluids to complex configurations with multiple passes, fins or baffles. Common heat exchangers include plate, shell and tube and cross flow types. A double tube heat exchanger is the simplest form of shell and tube type, where it is called a parallel flow type if both fluids flow in the same direction and a counter flow type if fluid flows occur in opposite directions. The shell and tube type is very common due to its relatively simple structure, high heat exchange rate and robustness. It consists of a shell containing a bundle of tubes and two caps covering the ends of the shell. Inside the tubes is a fluid which is most of the time a coolant such as water, and outside the tubes is oil, steam, etc. which needs to be cooled.

Lei et al. [1] recommends in their paper shell and tube heat exchangers with special type baffles to enhance heat transfer. They analyzed the fluid flow and the thermohydraulics using three-dimensional numerical simulation. They also numerically studied a shell and tube heat exchanger with conventional baffles and provided a detailed comparison of the different types. Kallannavar et al. [2] conducted a comprehensive study to explain the process parameters related to the design features of shell and tube heat exchangers. The researchers observed that heat transfer is better in the counter flow than in the parallel flow. In addition, counter flow heat exchangers with a flow rate of $0.024 \mathrm{~kg} / \mathrm{s}$ and a $45^{\circ}$ tube layout are observed to be a maximum of $26.7 \%$ more effective than parallel flow heat exchangers. The smallest percent difference of $0.14 \%$ is observed with a flow rate of $0.045 \mathrm{~kg} / \mathrm{h}$ and a $60^{\circ}$ tube layout. It is stated that the heat transfer rate is better with $30^{\circ}$ tube layout compared to other tube arrangements. Marzouk et al. [3] performed a comparative analysis of thermodynamics, hydraulic factors and performance calculation of shell and tube heat exchangers with five recommended application configurations. $U, \varepsilon, N T U, \eta$; as well as flow resistance (i.e. pressure drop) in various configurations. Mahendran [4] suggested that a shell and tube heat exchanger with a flower baffle plates should be an alternative heat exchanger for academic researchers and designers. He developed a threedimensional CFD model with detailed geometry. The entire modeling approach was used to make numerical calculations. He also created an experimental system to check the accuracy of the general modeling approach. The thermo-hydraulic performance of the shell and tube heat exchanger was numerically examined. Temperature 
distribution, pressure distribution and path lines were analyzed numerically. The analysis of the heat exchanger was found to be correct and was done using a flow simulation. Wang et al. [5] proposed a staggered-baffles shell and tube heat exchanger in their work. Numerical analysis of heat transfer performance and pressure drop was made for three types of shell and tube heat exchangers. They studied the effects of various parameters, including impact cutting of baffles and staggerring angle. Their results cover a wide range of issues such as the case of helical flow, heat transfer rate and pumping power consumption caused by pressure drop. He and Li [6] compared the performance of two different types of segmental baffled shell and tube heat exchangers. They used a numerical model to simulate and compare the thermohydraulics of these types with different basic types: segmental, helical, and flower baffles. Flow analysis on the shell side shows that the velocity distribution in the helical baffles is more homogeneous and uniform compared to the segmental and flower baffles. This results in fewer dead zones and less fluid recirculation areas compared to segmental baffles. In addition, the results show that the use of flower baffles can provide the best balance between heat transfer rate and effective pump performance compared to conventional segmental baffles and helical baffles. Yu et al. [7] proposed a new composite parallel flow shell and tube heat exchanger with clamping plate chamber and longitudinal eddy generators in their work. Thermohydraulic performance and flow structure of five different configurations were examined. They also performed a more detailed numerical analysis to examine the best thermal performance configuration using RSM. The effects of geometric parameters on thermohydraulic performance are discussed. The results were compared with previous studies. In the research of Arani and Moradia [8], they used the CF-3 method to investigate the thermohydraulics of shell and tube heat exchangers in a new 3D baffles and finned tubes. The pressure drop decreases due to the directional motion of the fluid along the tube axis. The results of the study show that changes to the common shell and tube heat exchanger significantly reduce the pressure drop on the shell side. Heat transfer is also increased due to the increased area of heat exchange with finned tubes. They also compared all the proposed types to demonstrate the thermohydraulic behavior of the baffles and finned tube combinations and presented the ratio of net heat transfer to pressure drop. In their work, El-Said and Abou Al-Sood [9] conducted an experimental comparative study on thermal, thermodynamic and hydraulic analyses, and performance evaluation of shell and tube heat exchangers with four different baffle configurations. One of the main conclusions drawn from their work is that the effect of a hybrid baffle configuration on $U, \varepsilon, N T U$ and $\eta$ is more pronounced than the other three types, This also includes that the flow side flow resistance for the hybrid baffle configuration is higher than the other configurations and that the hybrid baffle configuration is the best among other configurations, regardless of whether it has a negative impact on the pressure drop. Mohammadi et al. [10] studied six porous baffles with the same area in their studies to investigate the performance of the shell and tube heat exchanger. In this regard, they considered three values for permeability $\left(10^{-9} \mathrm{~m}^{2}, 10^{-12} \mathrm{~m}^{2}\right.$ and $\left.10-15 \mathrm{~m}^{2}\right)$, three values for porosity $(0.2,0.5$ and 0.8$)$ and three values for baffle cutting $(25 \%, 35 \%, 50 \%)$. Permeability of $10^{-9} \mathrm{~m}^{2}$ offers the highest heat transfer rate and the lowest pressure drop, while a low percentage (25\%) baffle cut can improve heat transfer. The high pressure drop generated is a limitation for engineers to design a lower percentage of the baffle. The $20 \%$ porosity also has the ability to transfer more heat and energy through the shell and tube heat exchanger, but creates a large pressure drop when baffle cuts are less than $40 \%$. They conducted a sensitivity analysis to evaluate the impact of each parameter on the outputs. The outcome of sensitivity analysis showed that baffle cut contributes the largest share in heat transfer and pressure drop, by having $88 \%$, and $71 \%$, respectively. Permeability is calculated as the second most important parameter, sharing $24 \%$ of the heat transfer rate and $7 \%$ of the pressure drop. For impact cutting, $27.58 \%, 10^{-9} \mathrm{~m}^{2}$ permeability and $21.68 \%$ porosity values are selected as optimal design points leading to high heat transfer rate and low pressure drop. Zhou et al. [11] proposed an accurate and simplified model to estimate the temperature distribution in the shell and tube heat exchanger based on differential theory. According to the baffle arrangement and tube passes, they split the heat exchanger into a series of elements connected by the tube side flow in series and shell side flow in parallel, and found that the proposed model could be successfully used for all shell and tube heat exchangers with straight or U tube types. A numerical study published by Pamuk [12] relates to a basic shell and tube heat exchanger without baffles. The study includes an analytical part that makes use of the basic convection theory and tables, formulas, and charts in the heat exchanger literature, as well as a CFD model of the shell and tube heat exchanger with the same dimensions of the heat exchanger provided in this article. This study shows that the numerical results can be successfully validated using an analytical approach. Validation of the basic model led to the study of methods to improve heat transfer in the shell and tube heat exchanger. A common way is to add baffles to the oil flow path, resulting in greater contact area with the cooling surfaces of the cooled fluid and greater mixing which increases the overall heat transfer coefficient, but with the disadvantage of higher pressure loss corresponding to increased pumping costs. 


\section{Numerical Model, Results and Discussion}

Both the basic version without baffles and the existing baffled models have a copper tube bundle with a $1 \mathrm{~mm}$ wall thickness of $8 \mathrm{~mm}$ inner diameter and a cylindrical outer steel shell with a $70 \mathrm{~mm}$ inner diameter and $5 \mathrm{~mm}$ wall thickness. In this study, the effect of adding a single baffle and three baffles to the oil flow path on heat transfer and pressure loss was investigated. The tube bundle is $180 \mathrm{~mm}$ long and consists of 36 tubes. The total length of the heat exchanger, including the semispherical end caps, is $260 \mathrm{~mm}$. The aim is to cool an oil flow with a flow rate of 1800 $\mathrm{kg} / \mathrm{h}$ entering from the top right, using water as a coolant with a flow rate of $450 \mathrm{~kg} / \mathrm{h}$ entering from the bottom right. The inlet temperatures of oil and water are $330^{\circ} \mathrm{K}$ and $300^{\circ} \mathrm{K}$ respectively. The kinematic viscosity of the oil is $20 \mathrm{cSt}$ and its density is $890 \mathrm{~kg} / \mathrm{m} 3$. It is assumed that the outer surface of the shell is insulated. The numerical model for basic geometry without baffles was validated based on these values.

The first step to using CFD is to create geometry. Figure 1 shows the geometry of the 3-baffle model. Due to the symmetry of geometry, only half of the domain (Figure 2) is examined to facilitate the efficient use of computing resources. The geometry of the heat exchanger used for the model consists of 6 parts: tubes, shell, front cap, back cap, oil flow domain and water flow domain.

The second step is to create a mesh for the computational domain. Mesh size and type, that is, the number of mesh elements, determines both the accuracy of the results and the execution time. The calculations were optimized through a series of experiments until they became invariant. The mesh structure (Figure 3) has almost 3 million mesh elements for half the domain.

The next step is problem setup which is the most critical one. Pressure-based steady-state solver is selected. The model under study is the fluid flow with defined inlet mass flowrates and temperatures, taking into account an realizable realizable k- $\square$ turbulent model coupled with the energy equation. ANSYS Fluent $\odot$ has been developed to solve all three conservation equations, namely conservation of mass, momentum and energy, also using a finite volume formulation:

$$
\begin{gathered}
\vec{\nabla} \cdot(\rho \vec{V})=0 \\
\vec{\nabla} \cdot(\rho \vec{V} \cdot \vec{V})=-\vec{\nabla} p+\vec{\nabla} \cdot(\overline{\bar{\tau}})+\rho \vec{g} \\
\vec{\nabla} \cdot([\vec{V}(\rho E+p)])=\vec{\nabla} \cdot\left[k_{e f f} \vec{\nabla} T-(\overline{\bar{\tau}} \cdot \vec{V})\right]
\end{gathered}
$$

In Equations 1, 2 and 3, $\overrightarrow{\boldsymbol{V}}$ is the velocity vector, $\boldsymbol{\rho}$ is the fluid density, $\overrightarrow{\boldsymbol{g}}$ is the gravitational acceleration vector, and $\boldsymbol{E}$ is the energy. Besides, $\overline{\bar{\tau}}$ represents the stress tensor and keff the effective thermal conductivity of fluids, in which both thermal properties and turbulence effects are taken into account. Inlet boundary conditions are the oil and water flowrates and temperatures mentioned above. The outlet boundary condition is atmospheric air pressure or zero pressure gauge. Under-relaxation factors are adjusted to prevent divergence although this procedure significantly slows down the convergence.

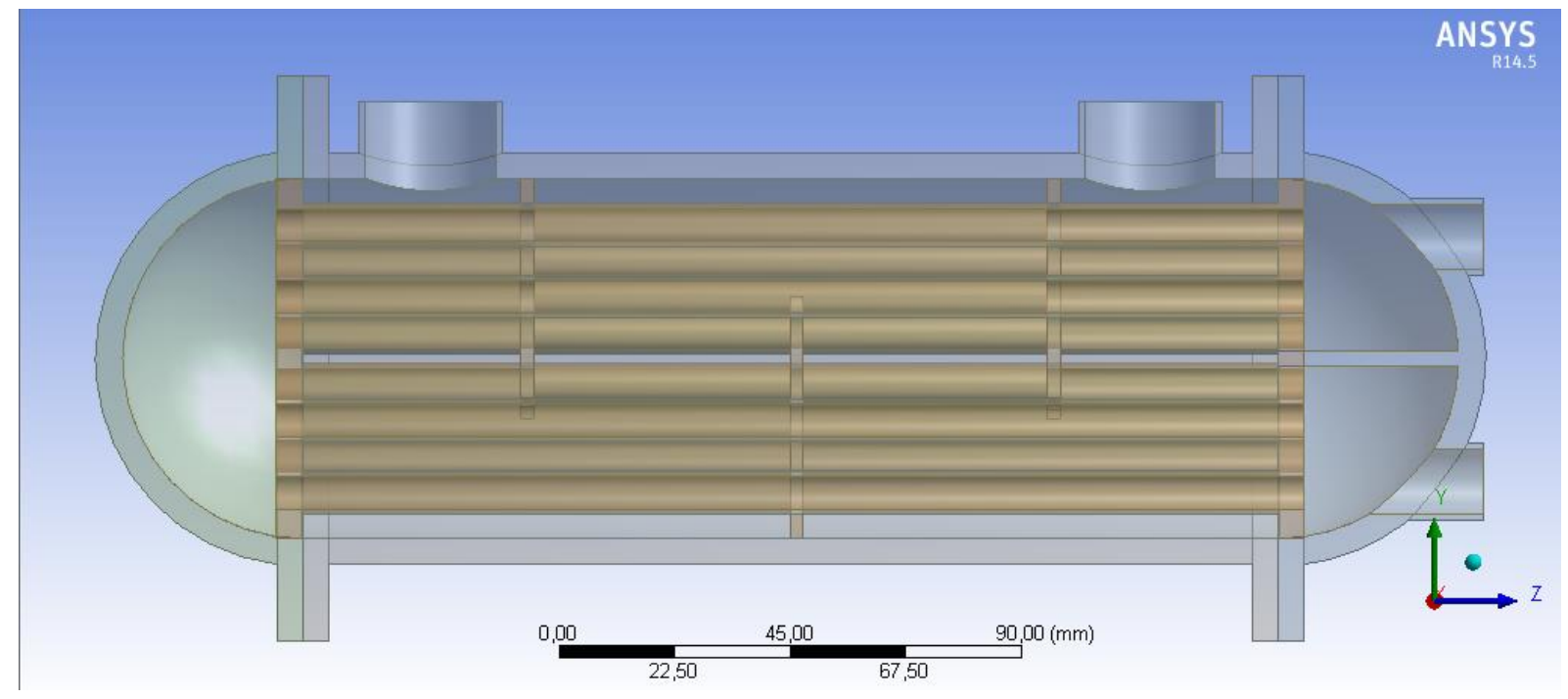

Figure 1. Layout of the shell tube heat exchanger with three baffles. 

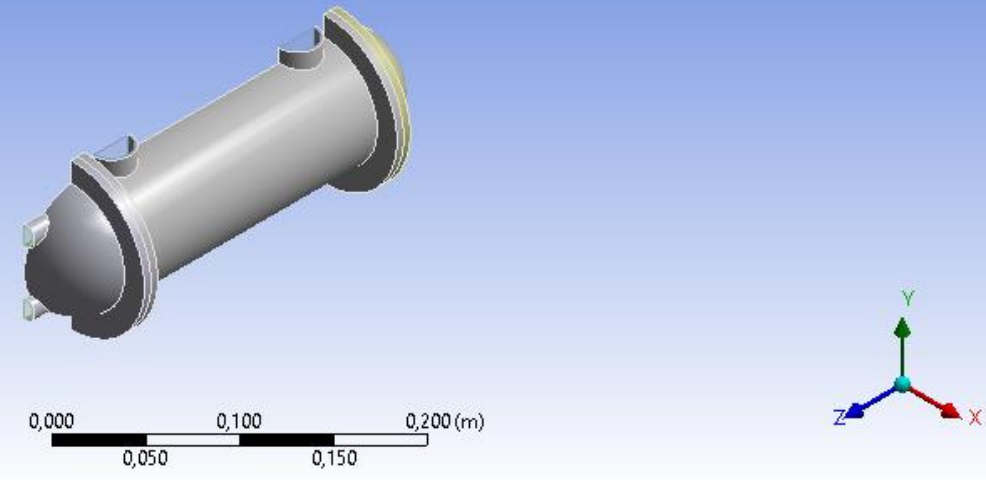

Figure 2. Geometry of the numerical model in ANSYS Fluent ${ }^{\odot}$.

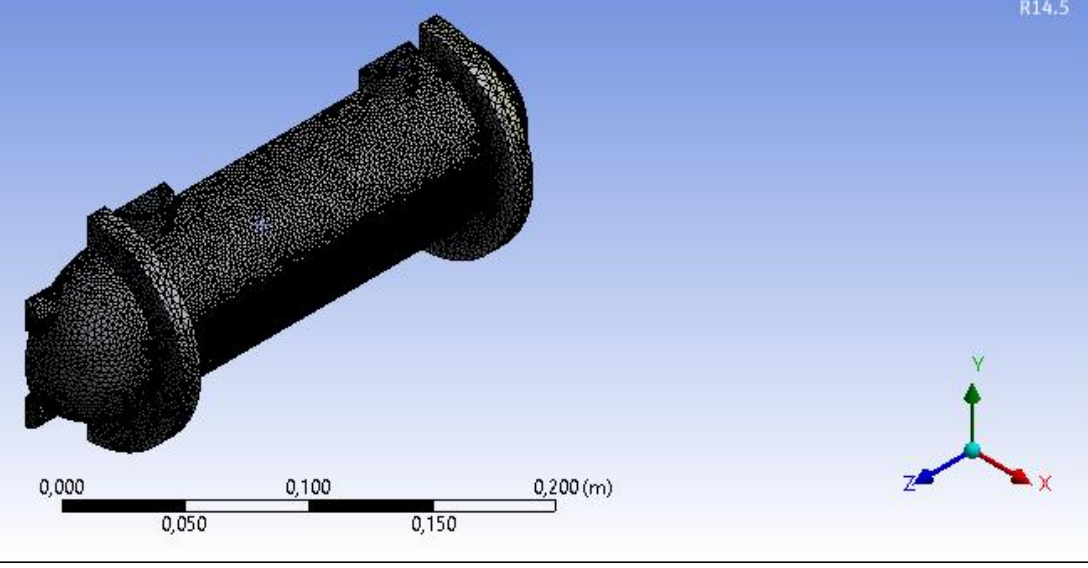

Figure 3. Mesh of the numerical model in ANSYS Fluent ${ }^{\circledR}$.

Figure 4-6 shows the temperature distributions for the basic type (without baffles) and the single and triple baffle models.

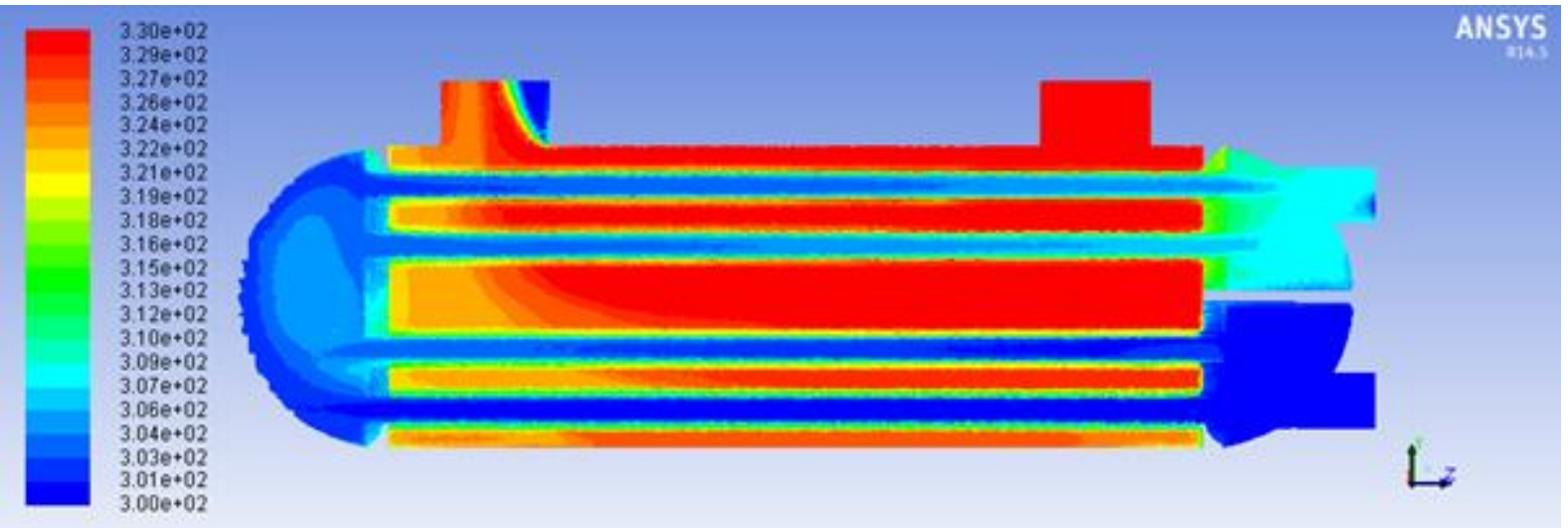

Figure 4. Temperature distribution in both fluids (Basic model without baffles). 


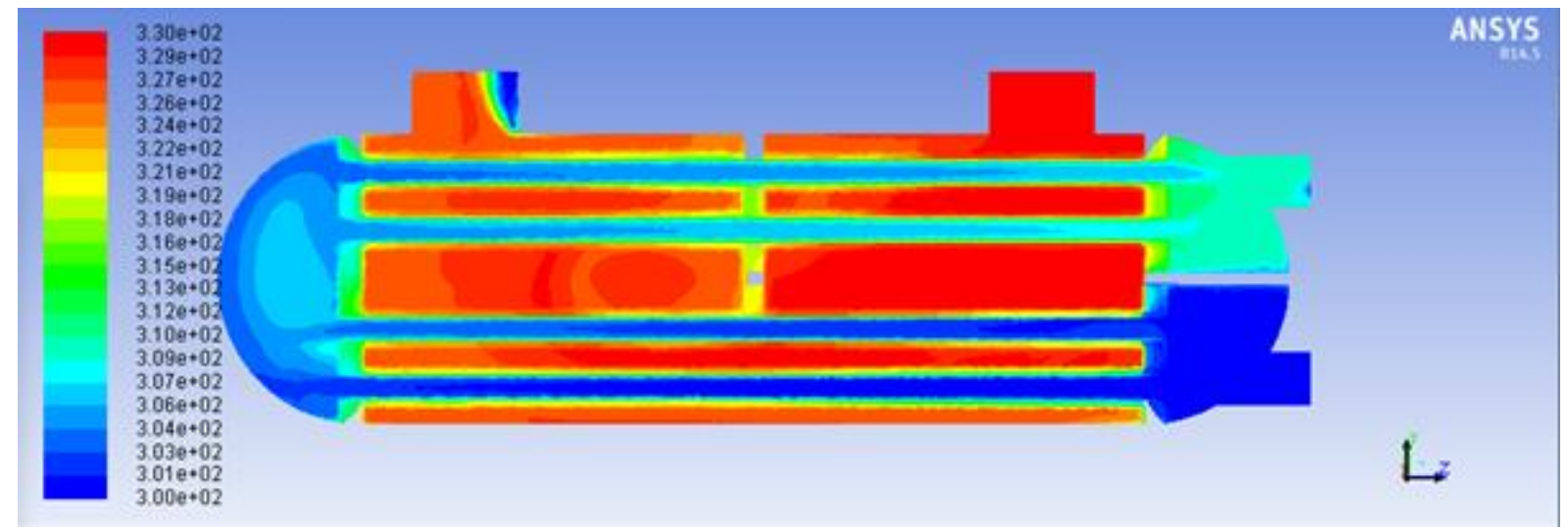

Figure 5. Temperature distribution in both fluids (Single baffle model).

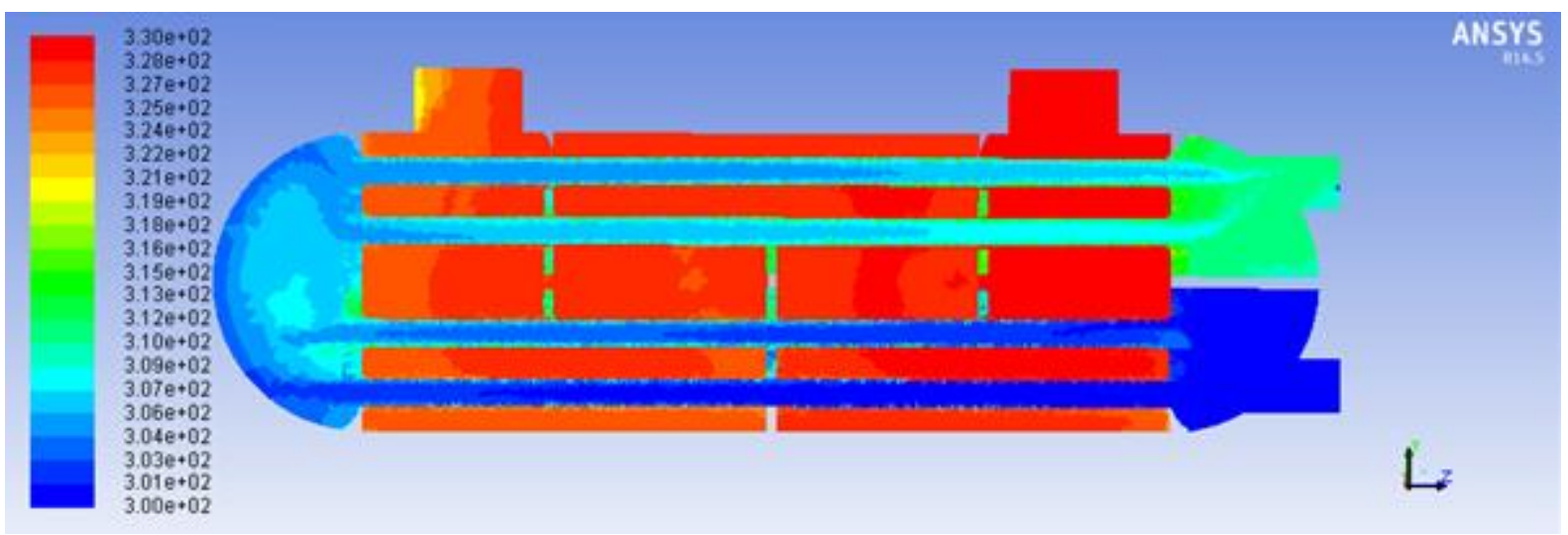

Figure 6. Temperature distribution in both fluids (Triple baffle model).

Figure 7-9 shows the velocity vectors of the oil flow for the basic type (without baffles) and for the single and triple baffle models.

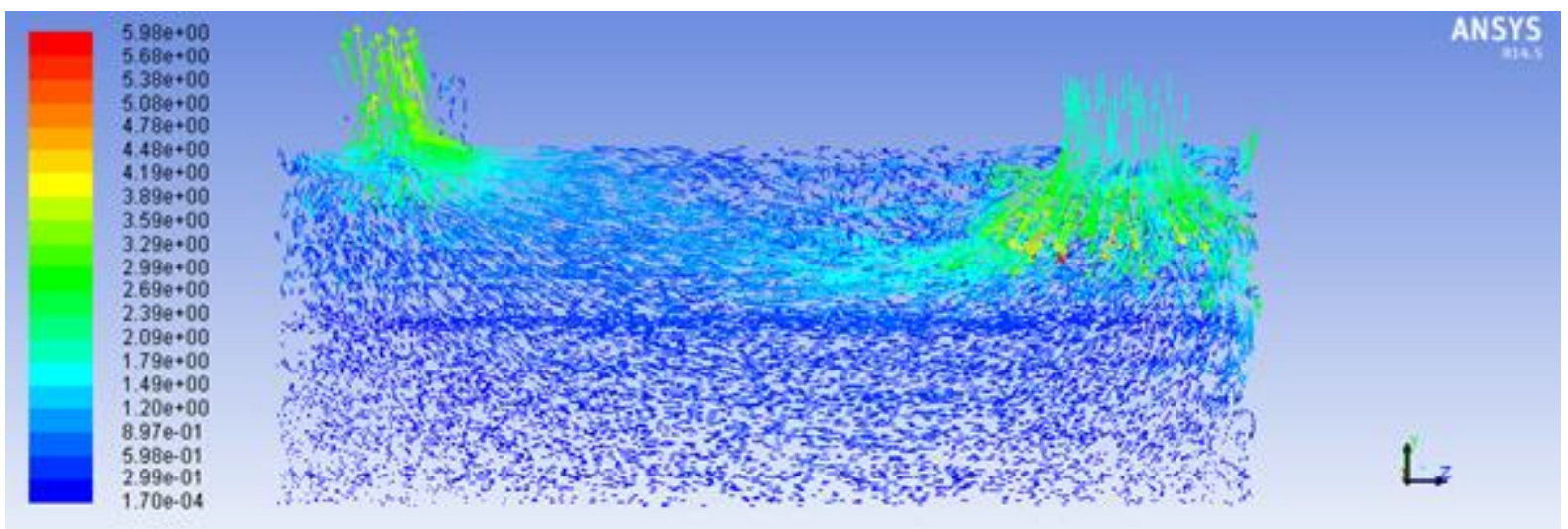

Figure 7. Velocity vectors in oil side (Basic model without baffles). 


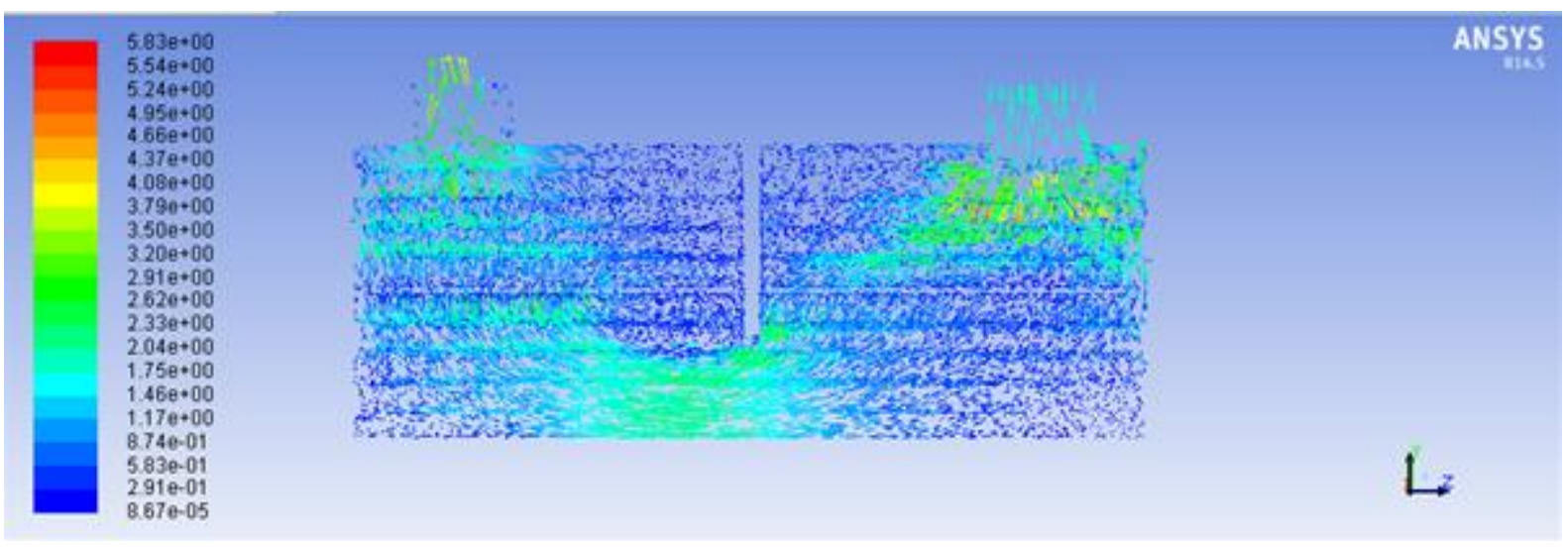

Figure 8. Velocity vectors in oil side (Single baffle model).

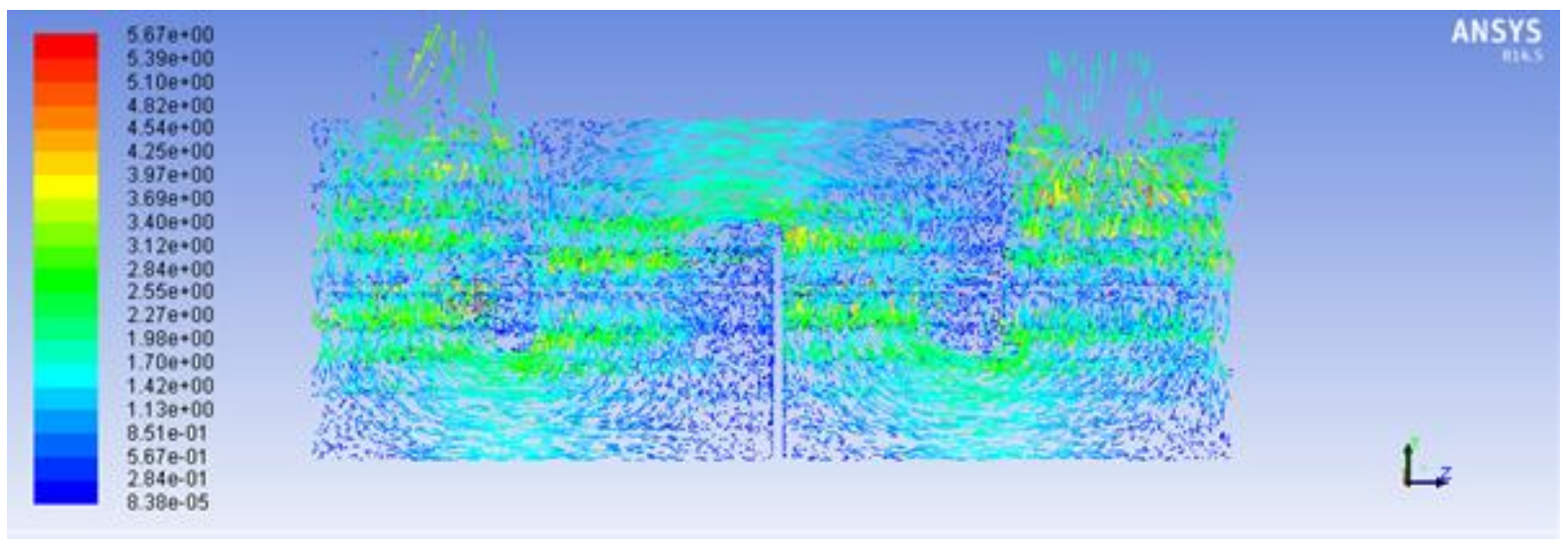

Figure 9. Velocity vectors in oil side (Triple baffle model).

The reliable numerical model of the simple type (without baffles) shell and tube heat exchanger show that the models with baffles must also be reliable, even though they are not validated. In all three models the conservation equations have been satisfied which are evident by the very small residuals and mass flow rates being exact as well as heat transfer rates being very close to each other in oil side and water side. Table 1 gives the comparison of heat transfer rates and pressure losses for the three cases. It can be seen that adding baffles can increase the heat transfer rate by almost $25 \%$. On the other hand pressure loss almost triples which may have to be taken into account as it means the pumping cost will also be three times the basic model. The asterisks in the last row denote the comparison between the basic model and triple baffle model.

Table 1. Thermal and hydrodynamic effects of baffles based on the oil side

\begin{tabular}{|l|c|c|c|c|}
\hline & $\begin{array}{c}\text { Heat Transfer } \\
\text { rate }(\mathrm{W})\end{array}$ & $\begin{array}{c}\text { Increase in Heat } \\
\text { Transfer rate }\end{array}$ & $\begin{array}{c}\text { Pressure Loss } \\
(\mathrm{Pa})\end{array}$ & $\begin{array}{c}\text { Increase in } \\
\text { Pressure Loss }\end{array}$ \\
\hline No baffles & 1961 & - & 10275 & - \\
\hline Single baffle & 2225 & $13 \%$ & 13700 & $33 \%$ \\
\hline Three baffles & 2443 & $9.8 \%-24.6 \%(*)$ & 30100 & $120 \%-193 \%(*)$ \\
\hline
\end{tabular}

\section{Conclusion}

In this numerical work, a numerical model for a Shell and Tube heat exchanger is studied by comparing the heat transfer and hydrodynamic results of the three different types, namely the basic type (no baffles), the single baffle type and the triple baffle type, using the commercial software ANSYS Fluent $\odot$. It was shown that CFD is a reliable tool for designing heat exchangers making it unnecessary to manufacture expensive prototypes and time consuming bench tests. 


\section{References}

[1] Y. Lei, Y. Li, S. Jing, C. Song, Y. Lyu, F. Wang, Design and performance analysis of the novel shell-and-tube heat exchangers with louver baffles, Applied Thermal Engineering 125 (2017) 870-879

[2] S. Kallannavar, S. Mashyal, M. Rajangale, Effect of tube layout on the performance of shell and tube heat exchangers, Materials Today: Proceedings November 2019, doi: 10.1016/j.matpr.2019.10.151

[3] S.A. Marzouka, M.M. Abou Al-Sood, E.M.S. El-Said, M.K. El-Fakharanya, Effect of wired nails circular-rod inserts on tube side performance of shell and tube heat exchanger: Experimental study, Applied Thermal Engineering 167(2020) 114696

[4] J. Mahendran, Experimental analysis of shell and tube heat exchanger using flower baffle plate configuration, Materials Today: Proceedings 21 (2020) 419-424

[5] X. Wang, N. Zheng, Z. Liu, W. Liu, Numerical analysis and optimization study on shell-side performances of a shell and tube heat exchanger with staggered baffles, International Journal of Heat and Mass Transfer 124 (2018) 247-259

[6] L. He and P. Li, Numerical investigation on double tube-pass shell-and-tube heat exchangers with different baffle configurations, Applied Thermal Engineering143(2018)561-569

[7] C. Yu, H. Zhang, M. Zeng, R. Wang, B. Gao, Numerical study on turbulent heat transfer performance of a new compound parallel flow shell and tube heat exchanger with longitudinal vortex generator, Applied Thermal Engineering 164(2020)114449

[8] A.A.A. Arani and R. Moradia, Shell and tube heat exchanger optimization using new baffle and tube configuration, Applied Thermal Engineering 157 (2019) 113736

[9] E.M.S. El-Said and M.M. Abou Al-Sood, Shell and tube heat exchanger with new segmental baffles configurations: A comparative experimental investigation, Applied Thermal Engineering 150 (2019) 803-810

[10] M. H. Mohammadi, H. R. Abbasi, A. Yavarinasab, H. Pourrahmani, Thermal optimization of shell and tube heat exchanger using porous baffles, Applied Thermal Engineering (2020), doi: j.applthermaleng.2020.115005

[11] G. Zhou, L.Y. Zhu, H. Zhu, S. Tu, J. Lei, Prediction of temperature distribution in shell-and-tube heat exchangers, Energy Procedia 61 ( 2014 ) 799 - 802

[12] M.T. Pamuk, CFD Simulation of a Shell and Tube Heat Exchanger, Presented at ICCPE'20 - 6th International Conference on Chemical and Polymer Engineering (ICCPE'20), August 16 - 18, 2020 